\title{
Design and Implementation of Super Wide Band Triple Band-Notched MIMO Antennas
}

\author{
Bazil Taha Ahmed ${ }^{1}$ D . Darío Castro Carreras ${ }^{1} \cdot$ Eduardo Garcia Marin $^{1}$
}

Accepted: 6 August 2021 / Published online: 23 August 2021

(c) The Author(s) 2021

\begin{abstract}
In this article, a triple band-notched super-wideband (SWB) monopole antenna is designed and manufactured. The measured working frequency band (out of the filters working band) ranges from 2.5 to $20 \mathrm{GHz}$. A single radiating element is utilized to analyze and implement various MIMO antennas, with isolation between the antenna ports higher than $15 \mathrm{~dB}$. Two parallel-fed elements SWB MIMO antenna and four parallel-fed elements SWB MIMO antennas are presented. Metallic barriers with different shapes are used to improve the isolation among ports from a low unacceptable value of $12 \mathrm{~dB}$ to a value higher than $20 \mathrm{~dB}$ within most of the working frequency band. S-parameters of the presented SWB MIMO antennas experimentally shows that antennas perform well up to $20 \mathrm{GHz}$, which is the highest frequency supported by the available Vector Network Analyzer used in the $\mathrm{S}$ parameters measurements. Satisfactory performance is observed up to $50 \mathrm{GHz}$ by computer simulations using the CST software.
\end{abstract}

Keywords UWB antennas $\cdot$ SWB antennas $\cdot$ MIMO antennas $\cdot$ Band-notched antennas

\section{Introduction}

A great number of researches addressing the design and performance study of Ultra-Wide Band (UWB) antenna have been done since the introduction of unlicensed UWB band of 3.1-10.6 GHz at 2002 for Ultra-Wide Band communications [1].

To get a high bit rate over a super wide operating band, super wide band Multiple-Input Multiple-Output (MIMO) antennas should be designed. Super wide band communication systems suffer from interference due to other widely deployed systems such as WLAN systems. Thus, the main objective of this work is to design SWB MIMO antenna with band reject capability. This can be done designing SWB MIMO antennas adding to it band reject filters.

Bazil Taha Ahmed

bazil.taha@uam.es

Darío Castro Carreras

dario.castro@estudiante.uam.es

Eduardo Garcia Marin

eduardo.garciam@uam.es

1 Escuela Politécnica Superior, Universidad Autónoma de Madrid, 28049 Madrid, Spain 
MIMO is a technique used to increase drastically the channel's bit rate. To do this, antennas with multiple isolated ports are used. Using $2 * 2$ MIMO antennas, bit rate can be doubled. Bit rate can be easily tripled or even quadrupled using $4 * 4$ MIMO antennas as shown in [2-4].

In [5-8], various UWB MIMO antennas working at different bands are presented. In MIMO systems, MIMO antennas are designed to have a high isolation among (between) their radiating elements (with a minimum of $13 \mathrm{~dB}$ and possible isolation of $20 \mathrm{~dB}$ or more). To satisfy this requirement, different effective isolation increment techniques are implemented.

In [9], a defected ground structure (DGS) is used to increase the isolation between the antenna elements. In [10], to increase the isolation between the antenna elements, a decoupling network is inserted between the elements of the MIMO antenna.

Some of MIMO antennas have a band-notch action to reject the interference from and to other communications systems. The most common notched band is the (5.1-5.9) GHz representing the WLAN higher band. Another band is the (3.2-3.8) GHz band representing the mid band of the sub- $6 \mathrm{GHz} 5 \mathrm{G}$ system operating bands. The third one is the X-band satellite communication services (XSCS) with a band of (7.2-8.4) GHz.

In [11], an UWB MIMO antenna that consists of two simple square monopole antennas with slotted ground plane structure is presented. Measurements of scattering parameters show that this antenna has a working band of (2.2-10.8) GHz. To reject the WiMAX (3.3-3.8) GHz working band, a band-notch filter consisting of a combination of U-shaped and L-shaped slots is effectively utilized. In [12], an UWB MIMO antenna is presented. Scattering parameters measurements show that the antenna works at a band of (3.1-11) GHz with a rejected band at the WLAN higher band of (5.15-5.85) GHz. Isolation between radiating elements is higher than $15 \mathrm{~dB}$.

In [13], an UWB MIMO antenna with band-notched characteristic is presented. Scattering parameters measurement results show that its working band extends from $2.85 \mathrm{GHz}$ up to $11.9 \mathrm{GHz}$, and that its rejection band is (5.1-6.0) GHz. Moreover, various novel types of UWB antennas are presented in $[14,15]$.

Super Wide-Band (SWB) MIMO antennas are MIMO antennas that work at frequencies higher than $10.6 \mathrm{GHz}$ and possibly reaching $20 \mathrm{GHz}$ or higher. They can be used to support the new $5 \mathrm{G}$ mobile communications (at the millimeter band) and other future communication systems.

In this article a single element triple band-notched SWB antenna and two triple bandnotched Super Wide Bandwidth MIMO antennas that work well up to $20 \mathrm{GHz}$ (representing the maximum working frequency of the measurement instruments that are available at our school) will be presented. Theoretically (using simulations), antennas work satisfactorily up to $50 \mathrm{GHz}$ (see "Appendix").

In Sect. 2 of this work, the design of various SWB MIMO antennas is explained. In Sect. 3, presents and discusses the antenna's measurements results. Finally in Sect. 4, conclusions are presented.

\section{SWB MIMO Antennas Design and Simulation Results}

SWB antenna is an antenna the works at a huge frequency band with an upper operating frequency to lower operating frequency of 10 or more.

In this section, two types of SWB MIMO (two ports and four ports) will be presented.

The dielectric material FR-35 with a dielectric constant of 3.5 and loss tangent of 0.0009 is used as a substrate in the design process of the three versions of SWB antennas 
(Single element SWB and two SWB MIMO antennas). The dielectric material has a thickness of $1.575 \mathrm{~mm}$.

It is well known that the antenna dimensions are related to its minimum operating frequency [16]. Antenna usually consists of a radiating element and a feeding line. Radiating element can have one of many possible shapes such as circular, semi-circular, rectangular, heptagonal, hexagonal or other shapes such as fractal shape. Input impedance of these radiating elements is usually higher than 100 ohms. Thus, a taper is required between the radiating element and the antenna connector to adapt the $50 \mathrm{ohms}$ system to the antenna high impedance in order to obtain a wide working band.

The geometry of the single element antenna without any filter is shown in Fig. 1. The radiating element has a circular shape. $50 \mathrm{ohms}$ feeding line with a length of Lf is followed by a trapezoidal taper that is used to match the $50 \mathrm{ohms}$ system impedance to the radiating element input impedance that is higher than $100 \mathrm{ohms}$. To get an antenna with good performance at $3.0 \mathrm{GHz}$; it should be designed to work well at a frequency band starting at $2.8 \mathrm{GHz}$ or little bit lower.

Table 1 gives the physical dimensions of the designed single elements SWB antenna.

The effective electrical length $\left(1_{\text {eff }}\right)$ of the SWB antenna is given by [17]:

$$
l_{e f f=}(2 R+L g+g+R p+R g)
$$

where.

- $\mathrm{R}$ is the radius of the circular radiating patch of the antenna

- $\mathrm{Lg}$ is the length of the ground plane

- $g$ is the vertical gap between the circular radiating element and the back side ground plane $=1 \mathrm{~mm}$.

- $\mathrm{Rp}$ is the electrical radius of the radiating patch $=\mathrm{R} / 4$.

- $\mathrm{Rg}$ is the electrical radius of the ground plane $=\mathrm{W} / 2 \pi$.

From the dimensions given in Table 1, the electrical length of this antenna is calculated to be $56.8 \mathrm{~mm}$.

The theoretical first resonance frequency of the SWB antenna (should be $3.0 \mathrm{GHz}$ or lower) is given by [17]:

$$
\mathrm{f}_{\min }(\mathrm{GHz})=\frac{144}{1_{\text {eff }}(\mathrm{mm})}
$$

Equation 2 gives a theoretical first resonance frequency of $2.53 \mathrm{GHz}$.

\subsection{CST Software is used in the Simulation and Optimization Process}

The simulated S11 of the single element SWB antenna is shown in Fig. 2. It can be noticed that its working band (with $\mathrm{S} 11$ lower than $-10 \mathrm{~dB}$ ) is $2.2-20 \mathrm{GHz}$ and that the first resonance frequency is near to $2.6 \mathrm{GHz}$.

It can be seen that the antenna works well (with $\mathrm{S} 11$ lower than $-10 \mathrm{~dB}$ ) within the 2.2 to $20 \mathrm{GHz}$ band. This makes the antenna susceptible to interference from other widely deployed systems. Thus, the next step is to introduce notch filters that work at three frequency bands, namely, 3.5, 5.5 and $7.5 \mathrm{GHz}$. The $3.5 \mathrm{GHz}$ filter is a half wavelength U-shaped slot within the radiating patch. The $5.5 \mathrm{GHz}$ filter consists of double U-shaped 
Fig. 1 Geometry of single element SWB antenna

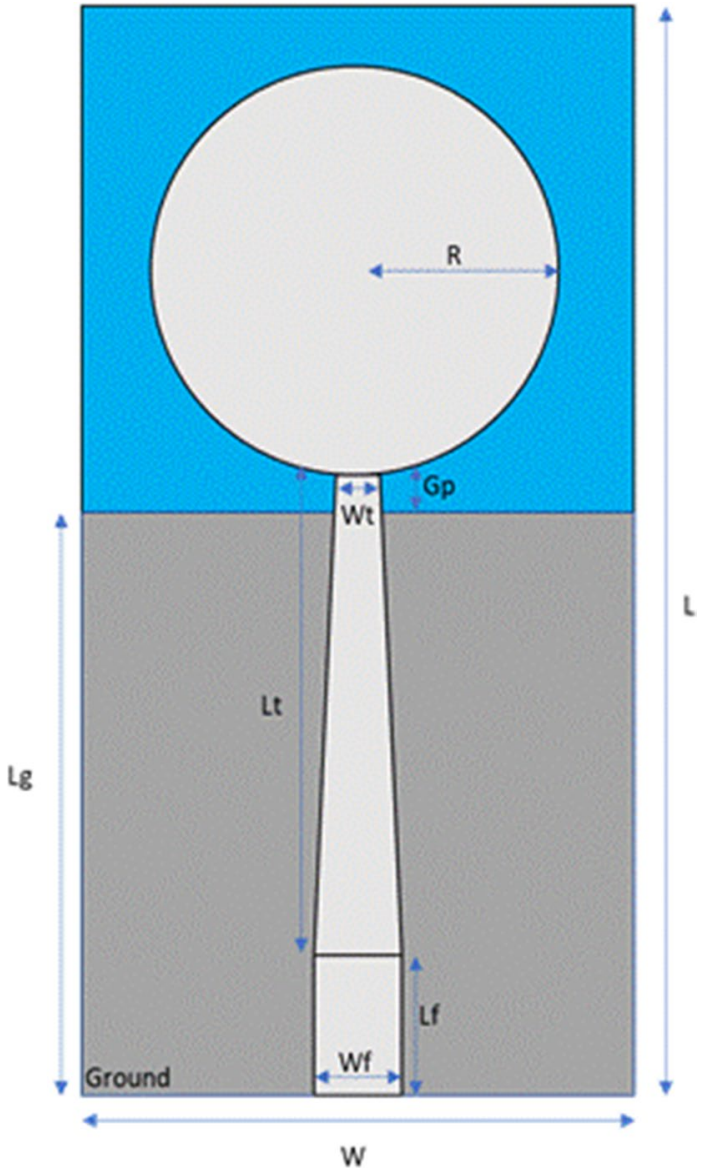

Table 1 Physical dimension of the single element SWB antenna

\begin{tabular}{ll}
\hline Parameter & Value $(\mathrm{mm})$ \\
\hline $\mathrm{W}$ & 35 \\
$\mathrm{~L}$ & 49 \\
$\mathrm{R}$ & 13 \\
$\mathrm{wf}$ & 3.4 \\
$\mathrm{Lf}$ & 6.0 \\
$\mathrm{Lt}$ & 16.0 \\
$\mathrm{Wt}$ & 1.5 \\
$\mathrm{Gp}$ & 1.0 \\
$\mathrm{Lg}$ & 21.0 \\
\hline
\end{tabular}

slots etched near to the feeding line. Finally, the $7.5 \mathrm{GHz}$ filter is a half wave U-shaped slot within the feeding line. Figure 3 shows the physical geometry of triple band-notched SWB antenna. 
SParameters [Magntude n dB]

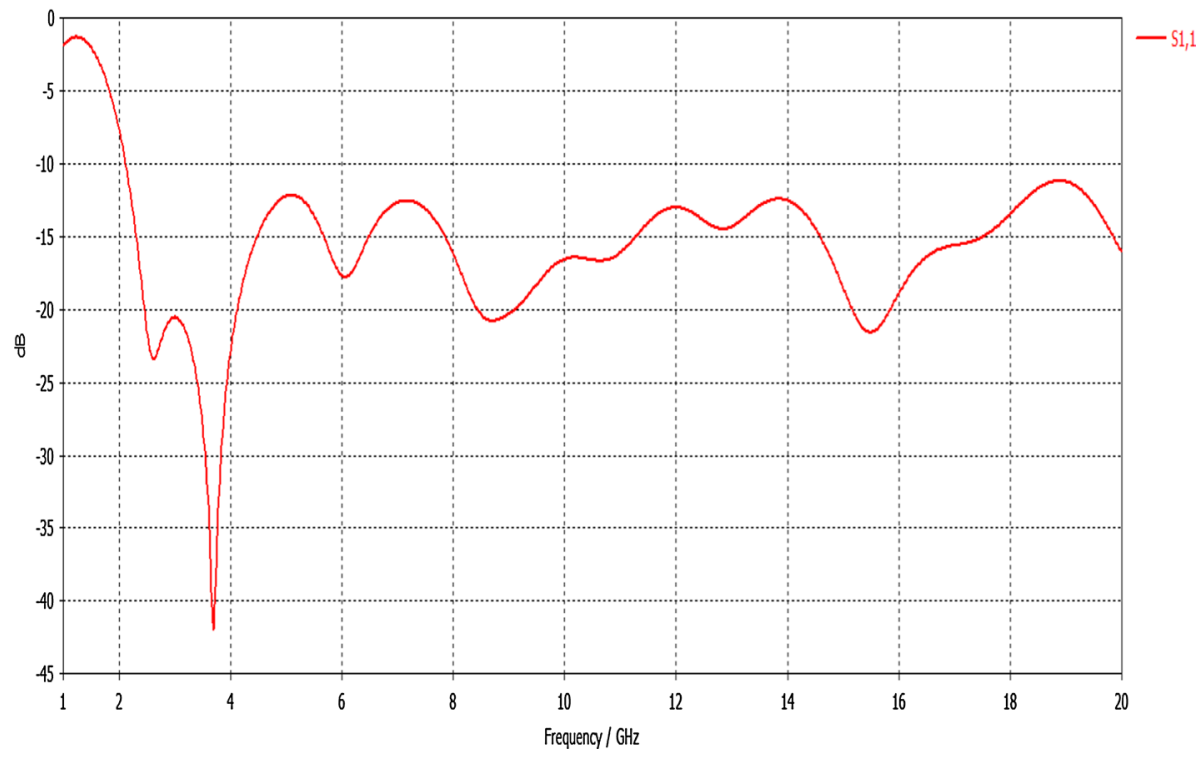

Fig. 2 Simulated S11 parameter of the SWB single element antenna

Total U-shaped slot length of filter 1 and 3 is given by:

$$
L_{U}=\frac{\lambda_{o} / 2}{\sqrt[2]{\frac{f r+1}{2}}}
$$

where.

- $\lambda \mathrm{o}$ is the free space wavelength at the filter center frequency.

- $\varepsilon_{\mathrm{r}}$ is dielectric constant $=3.5$

Table 2 shows physical dimension of the final band-notched SWB antenna.

Figure 4 depicts the simulated S11 parameter of the antenna. From it, it can be noticed that the first filter works at 3.3-3.7 GHz band. Second filter works at two subbands near to $5.5 \mathrm{GHz}$. The first sub-band extends from (5.02 to 5.34) $\mathrm{GHz}$ and the second one from (5.52 to 6.06) GHz. This filter has two sub-bands due to the different resonance frequency of its two horizontal parts. It can be seen that one part of it is over the ground mean while the other is only over the dielectric material. Also, the distance between the horizontal parts of this filter and the taper are different causing this double resonance of the filter. The third filter works at the band (6.99-8.07) GHz.

To construct SWB two elements MIMO antenna, a pair of the previously mentioned triple band-notched SWB antenna is used. The spacing between the two elements of the MIMO antenna is chosen in such a way to have isolation between them higher than $15 \mathrm{~dB}$ [16]. In order to increase the isolation between the antenna elements, T-shaped metallic parasitic line barrier printed within the gap between the radiating elements is used. Figure 5 shows the geometry of band-notched SWB two elements MIMO antenna with parallel feed. 
Fig. 3 Geometry of bandnotched simple SWB antenna

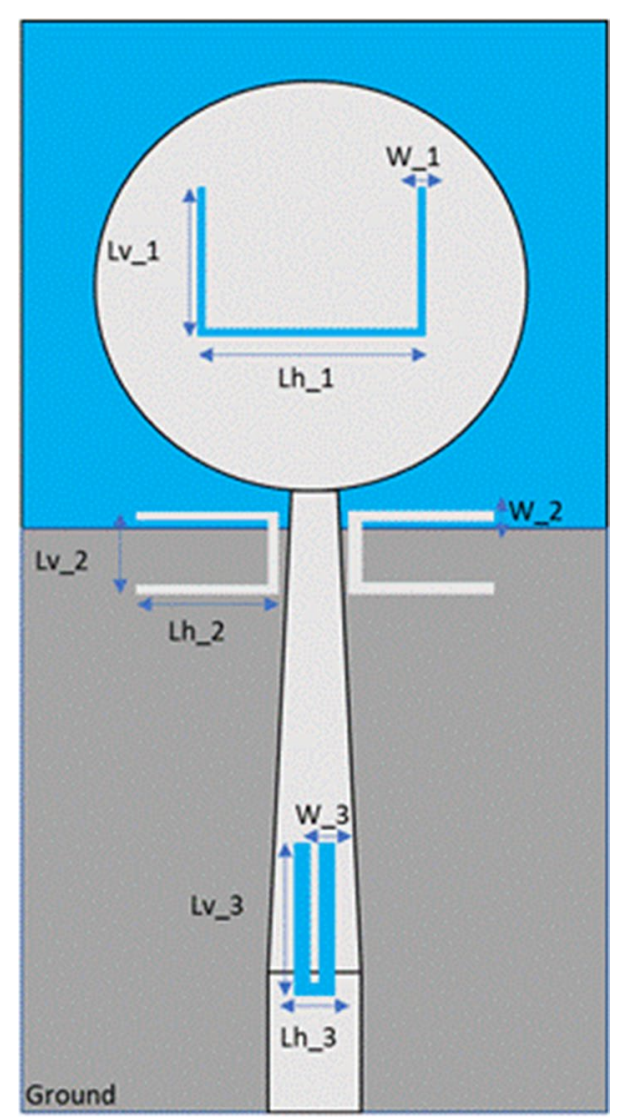

\begin{tabular}{lll}
\cline { 2 - 2 } $\begin{array}{l}\text { Table 2 Dimension of the band- } \\
\text { notched SWB antenna }\end{array}$ & Parameter & Value $(\mathrm{mm})$ \\
\cline { 2 - 3 } W1 & 0.3 \\
Lh1 & 11.4 \\
Lv1 & 9.06 \\
W2 & 0.3 \\
Lh2 & 8.87 \\
Lv2 & 3 \\
W3 & 0.8 \\
Lh3 & 1.8 \\
Lv3 & 6.9 \\
\hline
\end{tabular}

Table 2 Dimension of the bandnotched SWB antenna

Table 3 shows physical dimension of the final band-notched two elements SWB MIMO antenna.

Figure 6 represents the MIMO antenna simulated S11 and S21 parameters of the. First Filter working band is (3.19-3.81) GHz. Second filter sub-bands are (5.02-5.34) GHz and (5.51-6.06) GHz. Third filter working band is (6.99-8.08) GHz. Isolation higher than $20 \mathrm{~dB}$ can be noticed in the frequency band of (2.7-20) $\mathrm{GHz}$. 


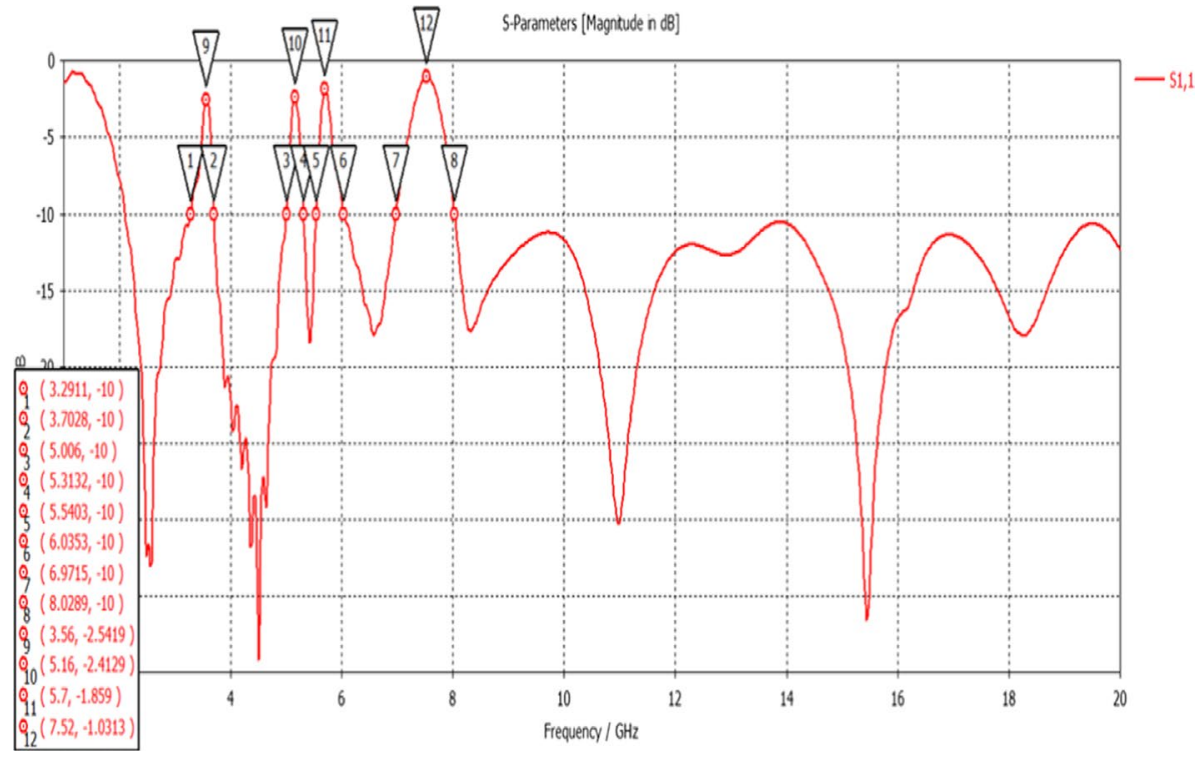

Fig. 4 Simulated S11 parameter of the triple band-notched SWB antenna

Figure 7 shows the four elements SWB MIMO antenna with up-down parallel feed configuration. Isolation increment is achieved using cross lines and a circular ring.

Table 4 gives some of the dimensions of the final four elements SWB MIMO antenna.

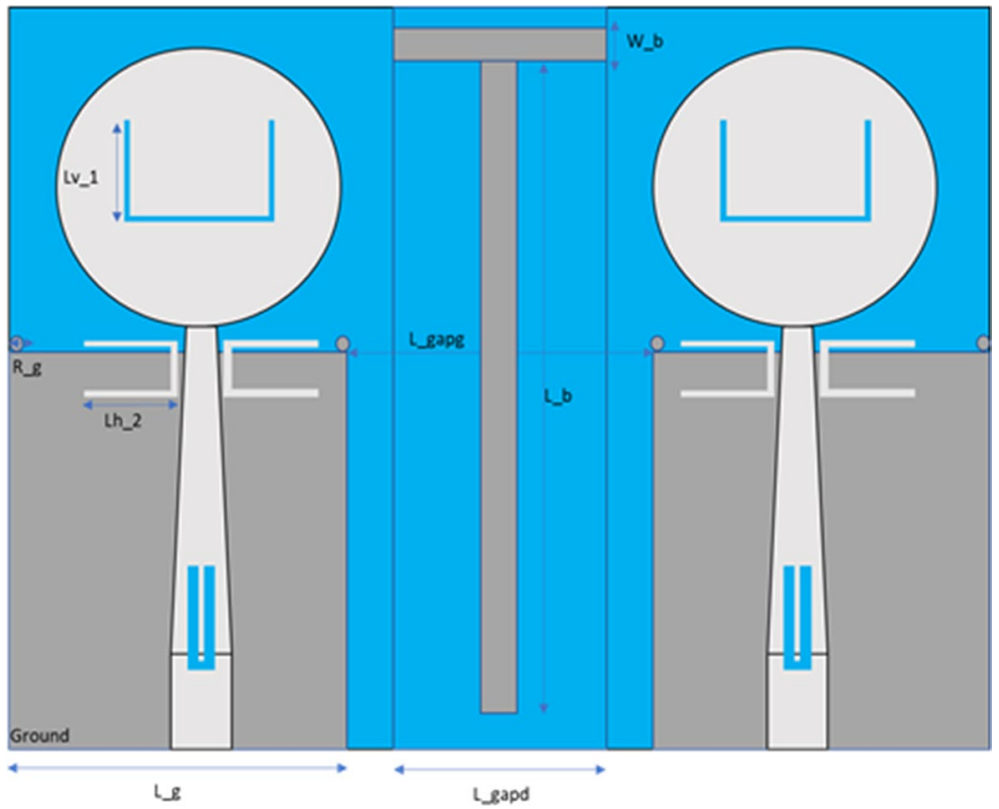

Fig. 5 Geometry of parallel feed band-notched two elements SWB MIMO antenna 
Table 3 Triple Band-notched two elements SWB antenna dimensions

\begin{tabular}{ll}
\hline Parameter & Value $(\mathrm{mm})$ \\
\hline Lgapg & 24 \\
Lgapd & 16 \\
Lb & 45 \\
$\mathrm{~Wb}$ & 2 \\
$\mathrm{Rg}$ & 0.5 \\
$\mathrm{Lv} 1$ & 8.86 \\
$\mathrm{Lh} 2$ & 8.57 \\
$\mathrm{Lg}$ & 31 \\
\hline
\end{tabular}

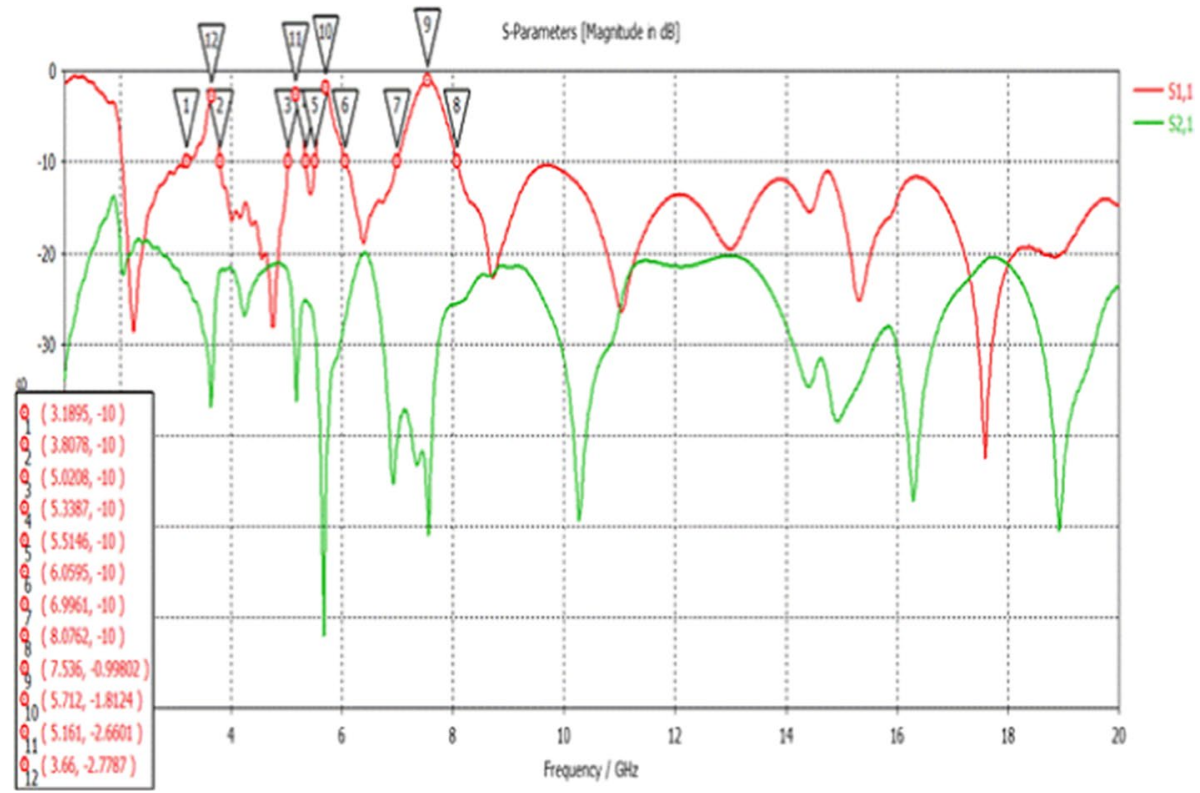

Fig. 6 Simulated S11 and S21 parameters of the triple band-notched SWB MIMO antenna

Figure 8 shows the simulated four S parameters of the designed MIMO antenna. It can be noticed that, the reflection parameter S11 is lower than $-10 \mathrm{~dB}$ outside the filter's bands. In the (3-20) GHz band, isolation (-S21, -S31 and -S41) between the elements is higher than $18 \mathrm{~dB}$. The working band of the first filter is (3.2-3.8) GHz. The sub-bands of the second filter are (5-5.35) GHz and (5.55-6.16) GHz. The working band of the third filter is (7.04-8.09) GHz.

\section{Measurements Results and Discussion}

The dielectric material FR-35 with a dielectric constant of 3.5 and loss tangent of 0.0009 is used as a substrate in the fabrication process. The used substrate has a thickness of $1.575 \mathrm{~mm}$. Antennas are fabricated using the LPKF S100 milling machine. 
Fig. 7 Four elements parallel feed SWB MIMO antenna

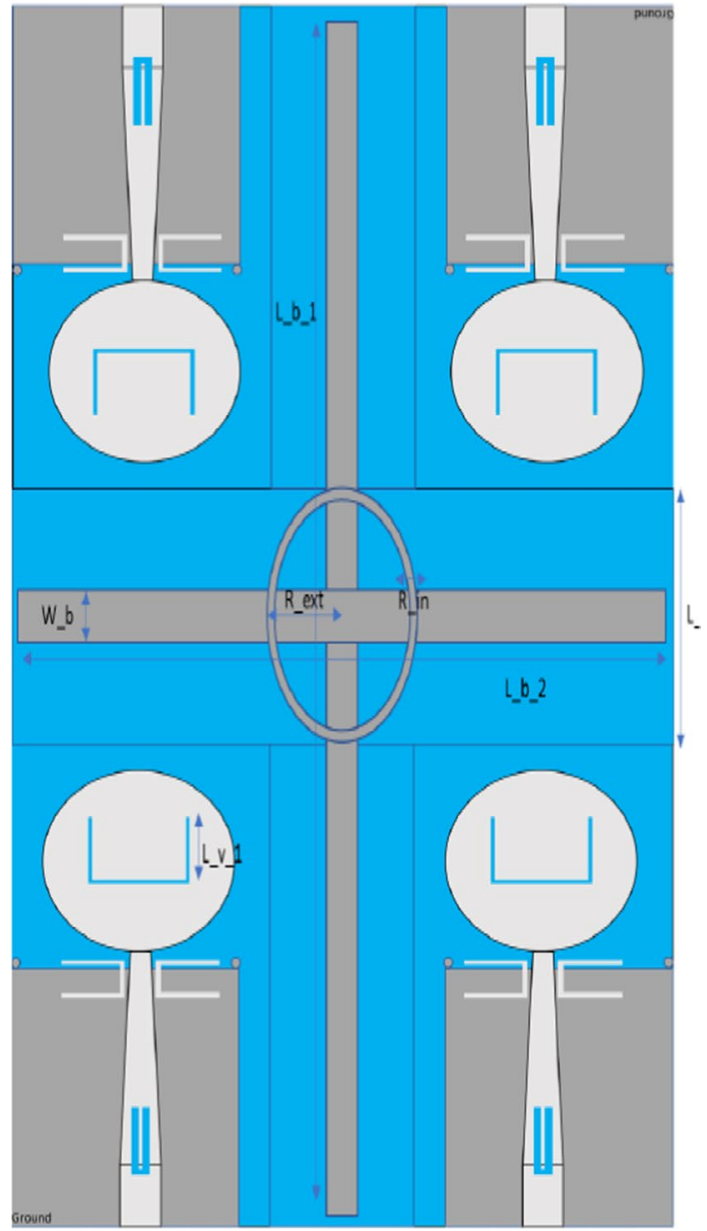

Table 4 Physical dimensions of the four elements SWB triple band-notched MIMO antenna

\begin{tabular}{ll}
\hline Parameter & Value $(\mathrm{mm})$ \\
\hline Lb1 & 116.5 \\
Lb2 & 84.5 \\
Wb & 2 \\
Lgapd & 20 \\
Lv1 & 8.96 \\
Rext & 10 \\
Rin & 9 \\
\hline
\end{tabular}

The Vector Network Analyzer (VNA) E5071C of Agilent with a maximum operating frequency of $20 \mathrm{GHz}$ is used to measure the $\mathrm{S}$ parameters of the fabricated antennas. An echoic chamber with instruments that work up to $18 \mathrm{GHz}$ is used to measure the radiation pattern of the fabricated antennas. 


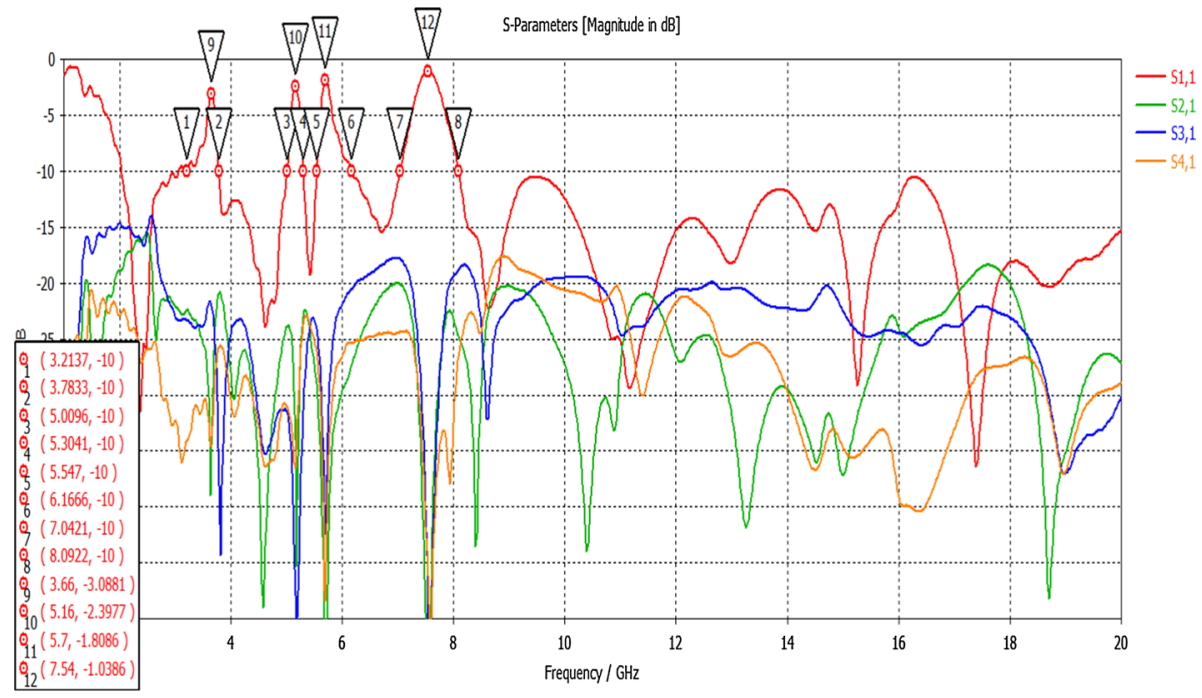

Fig. 8 Simulated S11, S21, S31 and S41 of the four elements SWB MIMO antenna

\subsection{S Parameter Measurements}

Figure 9 depicts a photograph of the front and rear views of the single element SWB antenna. SMA connector is used to connect the antenna with the measurement cable.

Figure 10 depicts the measured and simulated S11 parameter of the single element SWB antenna. From it, it can be seen the working bands of the three filters has been shifted to a higher frequencies. The discrepancy between the working bands of filters is due to the fabrication process and the change of the value of the dielectric constant at the high frequencies. Out of the filter's working bands, S11 is better (lower) than $-10 \mathrm{~dB}$.

Figure 11 shows the measured maximum gain of the single element antenna. It can be seen that the antenna maximum gain increases with the increment of frequency except at the filter's working bands. At $3 \mathrm{GHz}$, antenna gain is $3 \mathrm{dBi}$ increasing to $5.2 \mathrm{dBi}$ at $15 \mathrm{GHz}$.

Figure 12 represents a photograph of the two elements SWB MIMO antenna.

Figure 13 depicts the simulated and measured S11 parameter of the two elements SWB MIMO antenna. It can be noticed that the working bands of the three filters has been displaced to a higher frequencies. Out of the filter's working bands, S11 is lower than $-10 \mathrm{~dB}$. A way to have the filters working at the desired bands is to use little bit longer filters.

Figure 14 shows the measured and simulated S21 parameter of the two elements SWB MIMO antenna. It can be seen that the S21 is lower than $-20 \mathrm{~dB}$ at the major part of the working band with points at $-18 \mathrm{~dB}$.

Figure 15 shows the simulated and measured S12 parameter of the two elements SWB MIMO antenna. It can be noticed that the S12 is better (lower) than $-20 \mathrm{~dB}$ at almost the whole working band with some points at $-18 \mathrm{~dB}$.

Figure 16 illustrates the measured and simulated S22 parameter of the two elements SWB MIMO antenna. It can be seen that the working bands of the three filters has been shifted to a higher frequencies. Out of the filter's working bands, S22 is better (lower) than $-10 \mathrm{~dB}$. 
Fig. 9 Single element SWB antenna front and back views
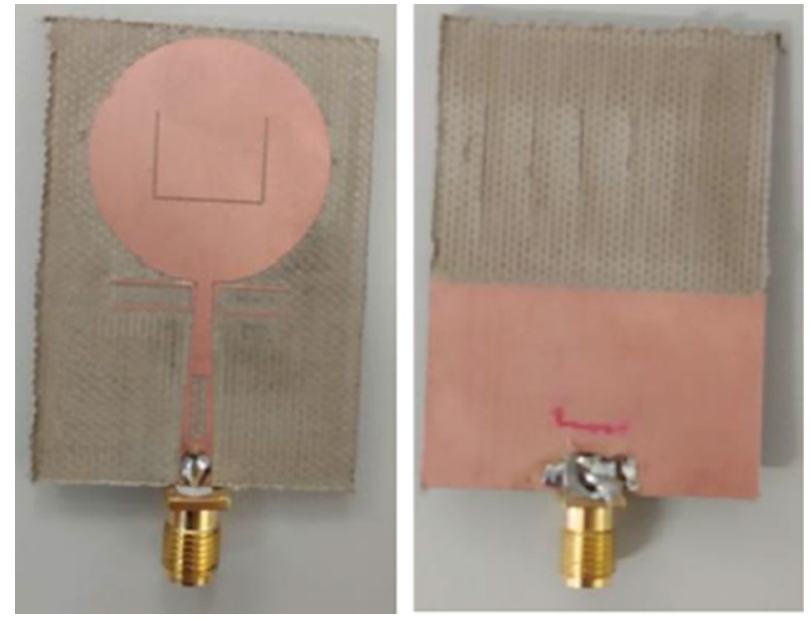

Fig. 10 Measured and simulated S11 parameter of the single element SWB antenna

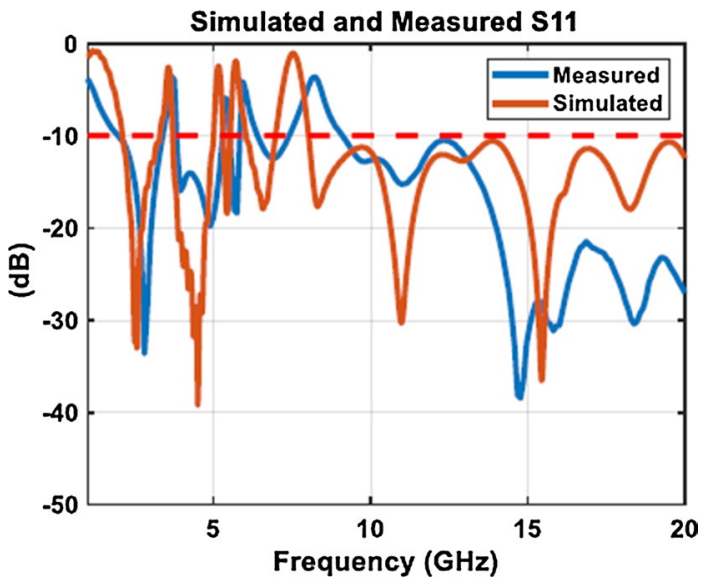

The Envelope Correlation Coefficient (ECC) is given by:

$$
E C C=\frac{\left|S_{11}{ }^{*} S_{12}+S_{21}{ }^{*} S_{22}\right|^{2}}{\left[1-\left(\left|S_{11}\right|^{2}+\left|S_{21}\right|^{2}\right)\right]\left[\left(1-\left|S_{12}\right|^{2}\left|S_{22}\right|^{2}\right)\right]}
$$

Out of notch filters bands, the Envelope Correlation Coefficient (ECC) of the two elements SWB MIMO antenna is lower than 0.015.

Figure 17 depicts the four elements SWB MIMO antenna.

Figure 18 illustrates the measured and simulated S11 parameter of the fabricated four elements SWB MIMO antenna. From it, it can be noticed that the working bands of the three filters has been shifted to a higher frequencies. Out of the filter's working bands, $\mathrm{S} 11$ is better (lower) than $-10 \mathrm{~dB}$.

Figure 19 depicts the measured and simulated S21 parameter of the four elements SWB MIMO antenna. It can be seen that the S21 is better (lower) than $-20 \mathrm{~dB}$ at the major part of the working band with some points at $-19 \mathrm{~dB}$. 


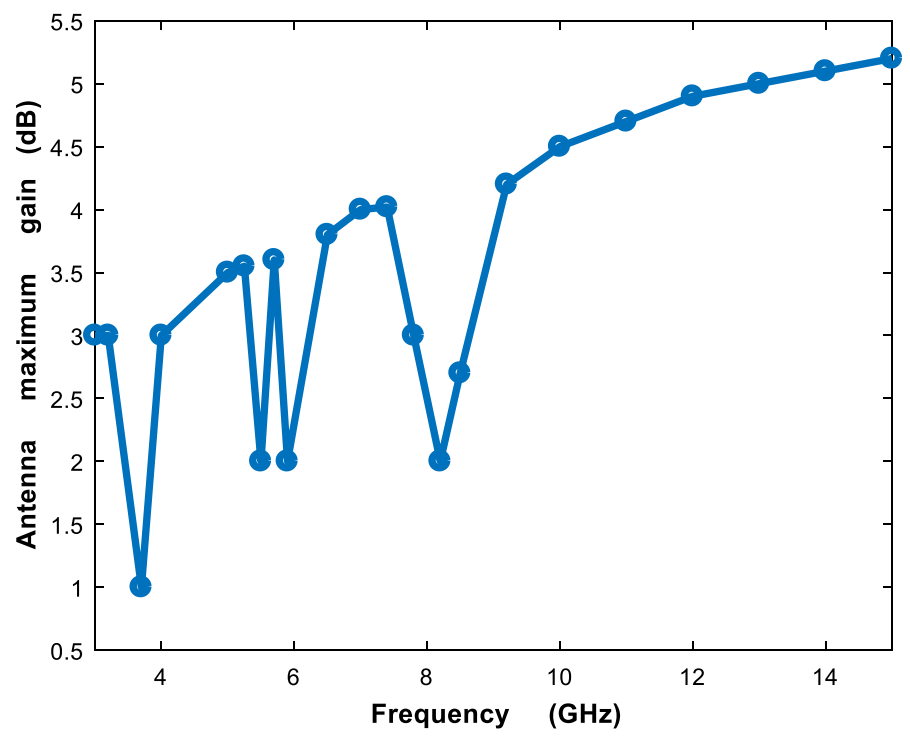

Fig. 11 Measured maximum gain of the single element antenna
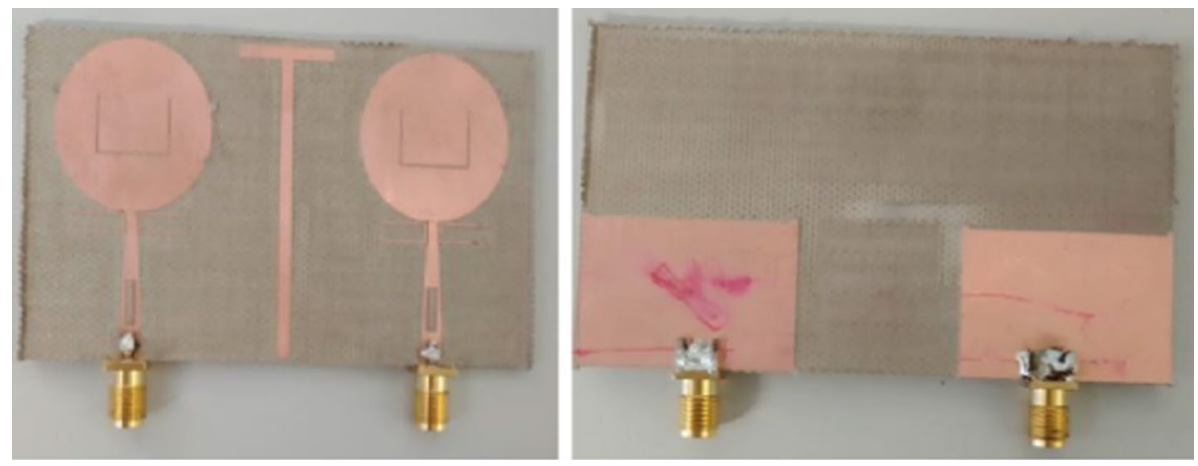

Fig. 12 Front and back views of the two elements SWB antenna

Figure 20 depicts the measured and simulated S31 parameter of the four elements SWB MIMO antenna. From it, it can be noticed that the measured S31 parameter is better (lower) than $-20 \mathrm{~dB}$ at the whole working band of the antenna.

Figure 21 shows the simulated and measured S41 parameter of the four element SWB antenna. From this figure, it can be seen that the measured S41 is lower than $-20 \mathrm{~dB}$ at the working whole working band of the antenna.

\subsection{Radiation Pattern Measurements}

Figure 22 shows the measred H-plane radiation pattern of the single elenment SWB antenna at 3, 4.5, 10 and $15 \mathrm{GHz}$ respectively. From this figure, it can be seen that at 
Fig. 13 Measured and simulated S11 parameter of the two element SWB antenna

Fig. 14 Simulated and measured S21 parameter of the two element SWB antenna

Fig. 15 Simulated and measured S12 parameter of the two element SWB antenna
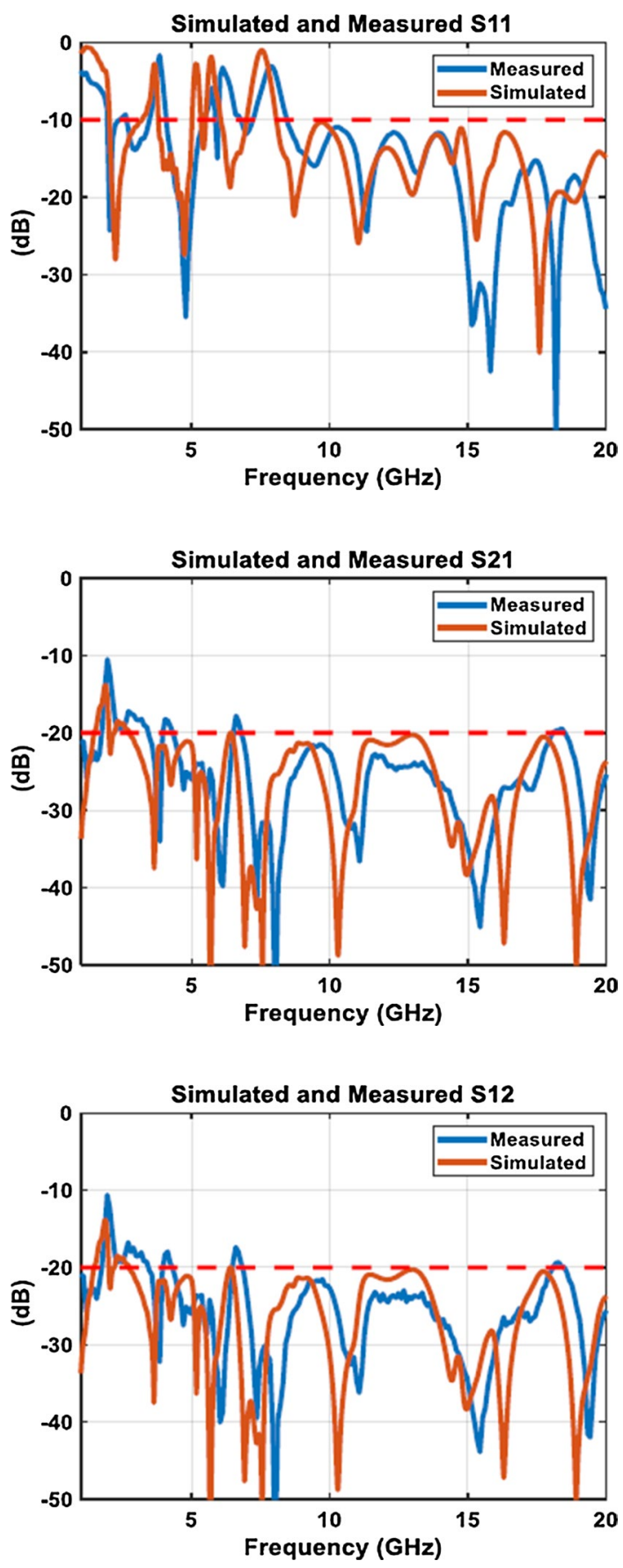
Fig. 16 Measured and simulated S22 parameter of the two elements SWB MIMO antenna
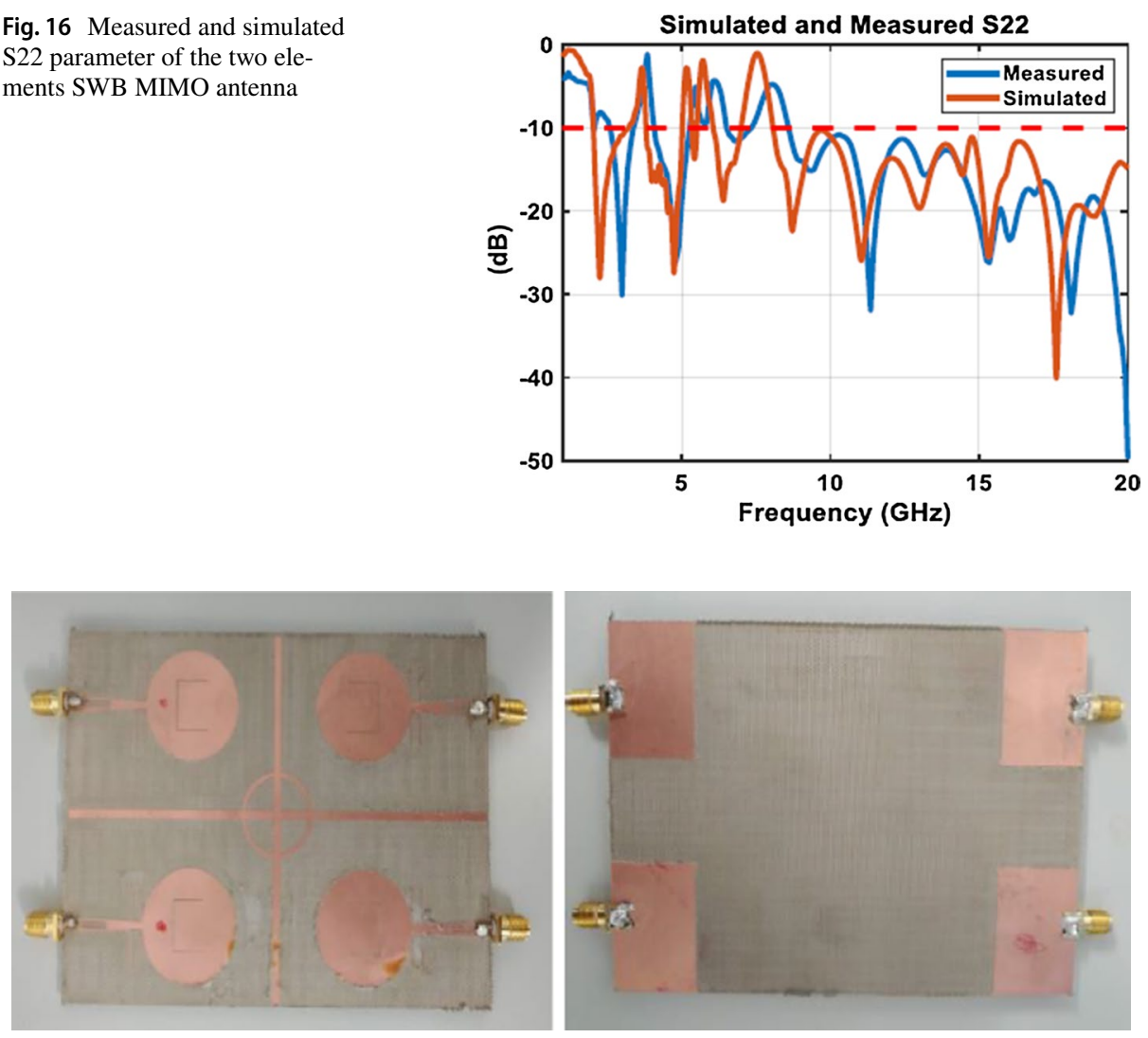

Fig. 17 Four elements SWB MIMO antenna

Fig. 18 Measured and simulated S11 parameter of the four elements SWB MIMO antenna

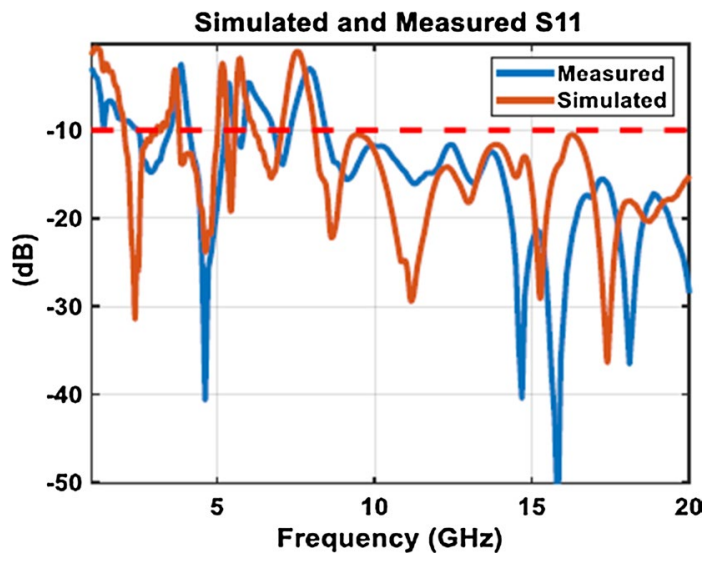


Fig. 19 Measured and simulated S22 parameter of the four elements SWB MIMO antenna

Fig. 20 Measured and simulated S31 parameter of the four element SWB antenna

Fig. 21 Measured and simulated S41 parameter of the four elements SWB MIMO antenna
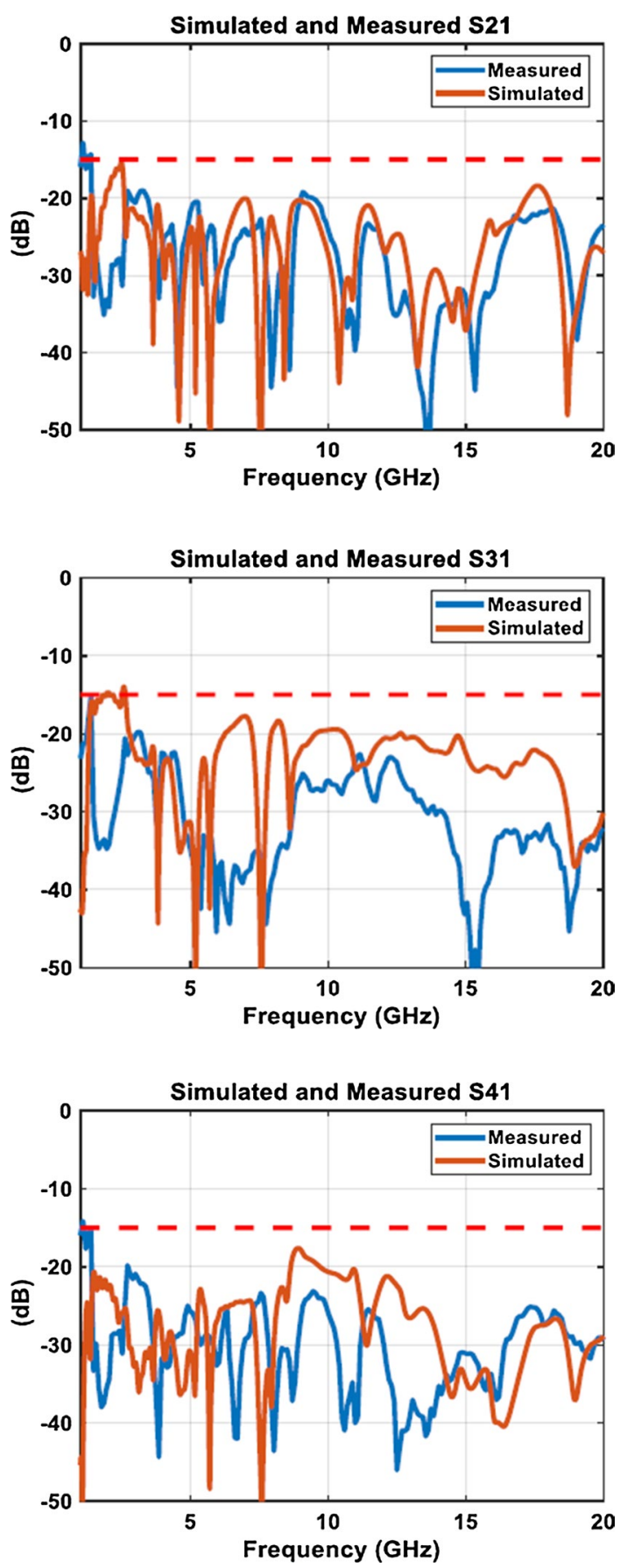
$3 \mathrm{GHz}$, the single element SWB antenna is almost omnidirectional. Also it can be seen that at $4.5 \mathrm{GHz}$, the single eleemnt SWB antenna is almost omnidirectional. At $10 \mathrm{GHz}$, the $\mathrm{H}$-plane has its maximun gain at $300^{\circ}$. Finally, at $15 \mathrm{GHz}$, the $\mathrm{H}$-plane has its maximun gain at $270^{\circ}$. E-plane radiation pattern has the well known 8-like shape.

Now the measured radiation pattern of the two elements SWB MIMO antenna will be presented. Figure 23 shows the measured H-plane radiation pattern of one of the two elements elenment at 3, 4.5, 10 and $15 \mathrm{GHz}$ respectively. From this figure, it can be seen that at $3 \mathrm{GHz}$, the single element SWB antenna is almost omnidirectional with its minimum value at $270^{\circ}$ which represents the direction of the other element. At $5 \mathrm{GHz}$, the single element SWB antenna is almost omnidirectional with its minimum value at $270^{\circ}$. At $10 \mathrm{GHz}$, the $\mathrm{H}$-plane radiation pattern is little bit directive with its minimum value at $270^{\circ}$. At $15 \mathrm{GHz}$, the H-plane radiation pattern is little bit directive. Its value at $270^{\circ}$ is $8 \mathrm{~dB}$ lower than the maximum value. E-plane radiation pattern has the well known 8-like shape.

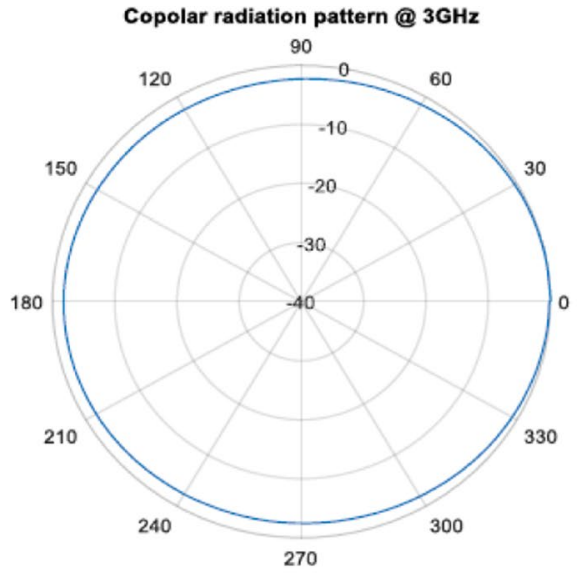

(a) H-plane measured at $3 \mathrm{GHz}$

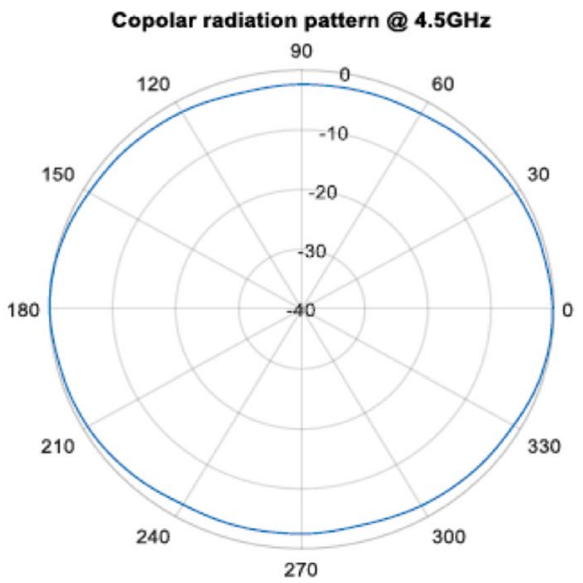

(b) H-plane measured at $4.5 \mathrm{GHz}$

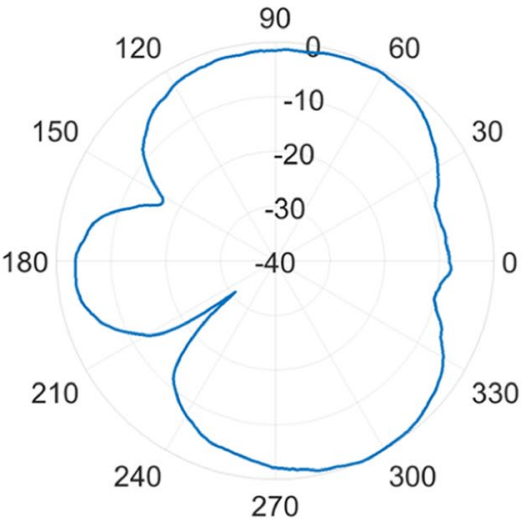

(c) H-plane measured at $10 \mathrm{GHz}$

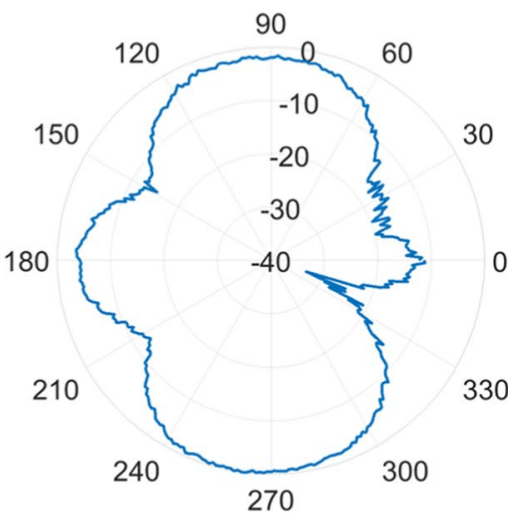

(d) H-plane measured at $15 \mathrm{GHz}$

Fig. 22 Measured H-plane radiation pattern of the single elenment SWB antenna at 3, 4.5, 10 and $15 \mathrm{GHz}$ 


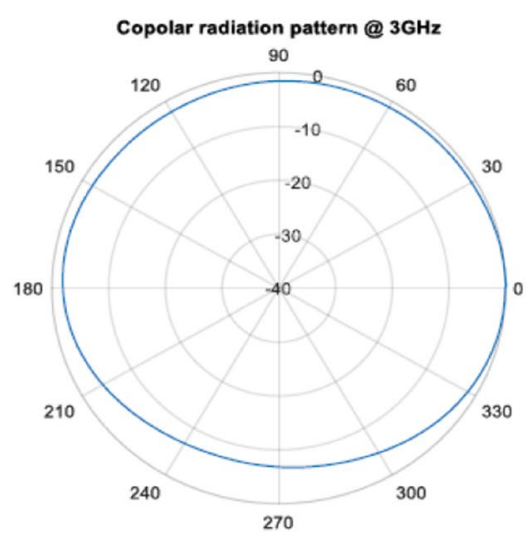

(a) Measured H-plane at $3 \mathrm{GHz}$

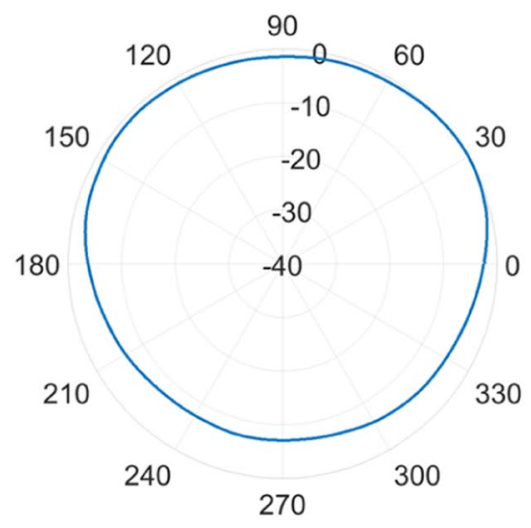

(b) Measured H-plane at $4.5 \mathrm{GHz}$

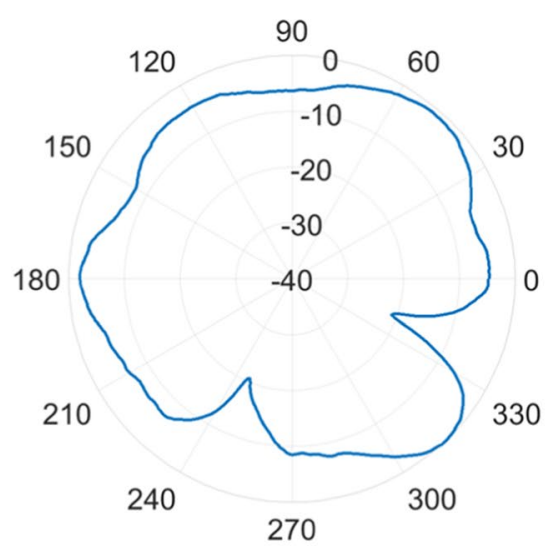

(c) Measured H-plane at $10 \mathrm{GHz}$

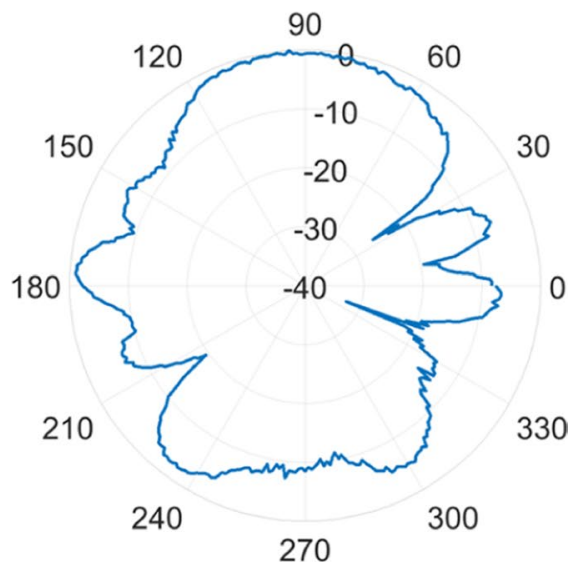

(d) Measured H-plane at $15 \mathrm{GHz}$

Fig. 23 Measured H-plane radiation pattern of the two elements SWB MIMO antenna at 3, 4.5, 10 and $15 \mathrm{GHz}$

Next the four elements SWB MIMO antenna measured radiation pattern will be presented. Figure 24 shows the measured H-plane radiation pattern of one of the four elements elenment at 3, 4.5, 10 and $15 \mathrm{GHz}$ respectively.

From this figure, it can be seen that at $3 \mathrm{GHz}$, the single element SWB antenna is almost omnidirectional with its minimum value at $270^{\circ}$ which represents the direction of the other element. At $5 \mathrm{GHz}$, the single element SWB antenna is almost omnidirectional with its minimum value at $270^{\circ}$. At $10 \mathrm{GHz}$, the $\mathrm{H}$-plane radiation pattern is little bit directive. Its value at $270^{\circ}$ is $8 \mathrm{~dB}$ lower than the maximum value. Finally, at $15 \mathrm{GHz}$, the $\mathrm{H}$-plane radiation pattern is little bit directive. Its value at $270^{\circ}$ is $8 \mathrm{~dB}$ lower than the maximum value.

It has been noted that crosspolar normalized gain pattern is $15-20 \mathrm{~dB}$ lower than the copolar normalized gain pattern. 


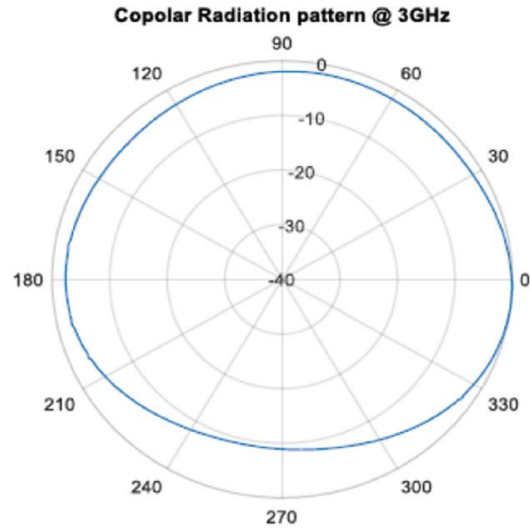

(a) Measured H-plane at $3 \mathrm{GHz}$

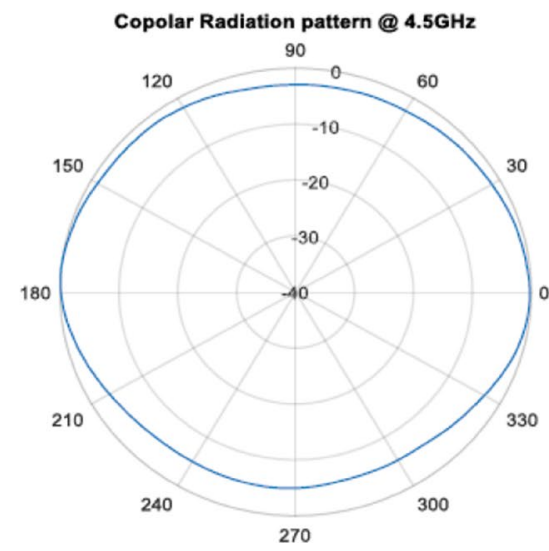

(b) Measured H-plane at $4.5 \mathrm{GHz}$

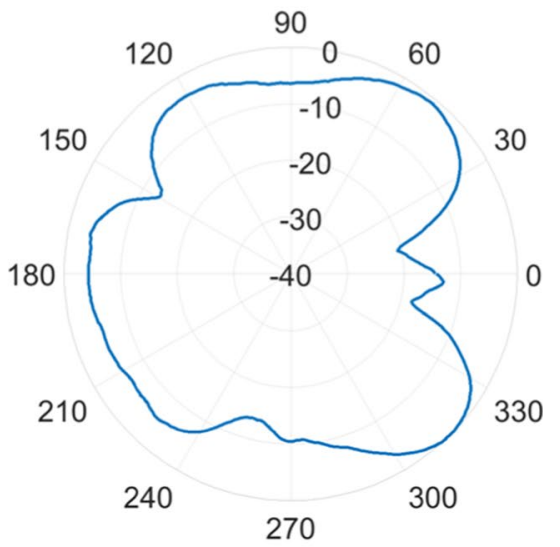

(c) Measured H-plane at $10 \mathrm{GHz}$

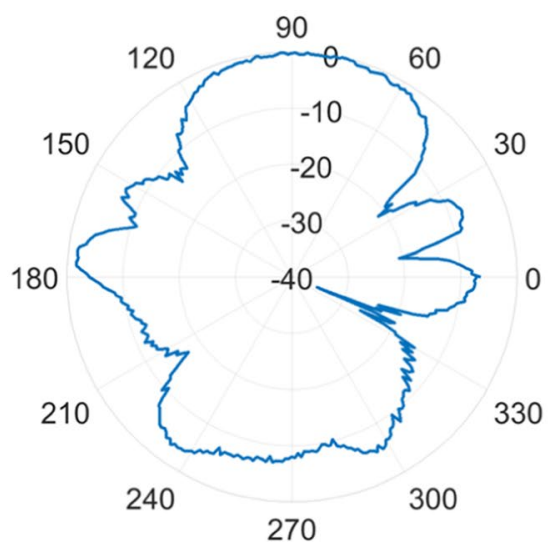

(d) Measured H-plane at $15 \mathrm{GHz}$

Fig. 24 Measured H-plane radiation pattern of the four elements MIMO antenna at 3, 4.5, 10 and $15 \mathrm{GHz}$ 
Table 5 Comparison between proposed antenna and other works

\begin{tabular}{lll}
\hline Reference & Operating band $(\mathrm{GHz})$ & Notched bands $(\mathrm{GHz})$ \\
\hline 18 & $(3.0-11.0)$ & $(3.3-3.8)$ and $(5.0-6.0)$ \\
19 & $(2.2-10.8)$ & $(2.5-2.69)$ and $(3.3-4.2)$ \\
20 & $(3.4-11.8)$ & $(5.02-5.97)$ and $(7.23-7.72)$ \\
21 & $(2.95-12.00)$ & $(3.2-3.8)$ and $(5.15-5.85)$ \\
This Work & $(2.5-20)$ & $(3.2-3.8),(5.00-5.35)$, \\
& & $(5.55-6.16)$ and \\
& & $(7.04-8.09)$ \\
\hline
\end{tabular}

Table 5 presents the comparison between the proposed antenna and other works in terms of working band and number of notched band. It can be observed from this table that the proposed antenna has the higher working band.

\section{Conclusions}

In this work, triple band-notched (SWB) MIMO antennas have been designed and manufactured. It has been shown that, the measured working frequency band (out of the filters working band) ranges from 2.5 to $20 \mathrm{GHz}$. A single radiating element SWB antenna has been used as the first pass to design several SWB MIMO antennas, with isolation between (among) the antenna ports better (higher) than $15 \mathrm{~dB}$. Two-element and four parallel-fed SWB MIMO antennas have been presented. Metallic barriers have been used to improve the isolation among ports from a low unacceptable value of $12 \mathrm{~dB}$ to better (higher) than $20 \mathrm{~dB}$ within almost the whole working frequency band. Measured S-parameters of the presented SWB MIMO antennas shows good performance up to $20 \mathrm{GHz}$, which is the highest frequency supported by the available Vector Network Analyzer. Satisfactory performance has been observed up to $50 \mathrm{GHz}$ through computer simulations using the CST software.

\section{Appendix}

Measurements of S parameters have been done using the Vector Network Analyzer (VNA) E5071C of Agilent with a maximum operating frequency of $20 \mathrm{GHz}$. To get an idea about the performance of the MIMO antenna at higher frequencies, simulations are done up to $50 \mathrm{GHz}$.

Figure 25 shows the simulated S11 of the single element antenna without notch filters. It can be seen that theoretically, the antenna works well (with S11 lower than $-10 \mathrm{~dB}$ ) up to $50 \mathrm{GHz}$. 
S.Parameters [Magntude in d B]

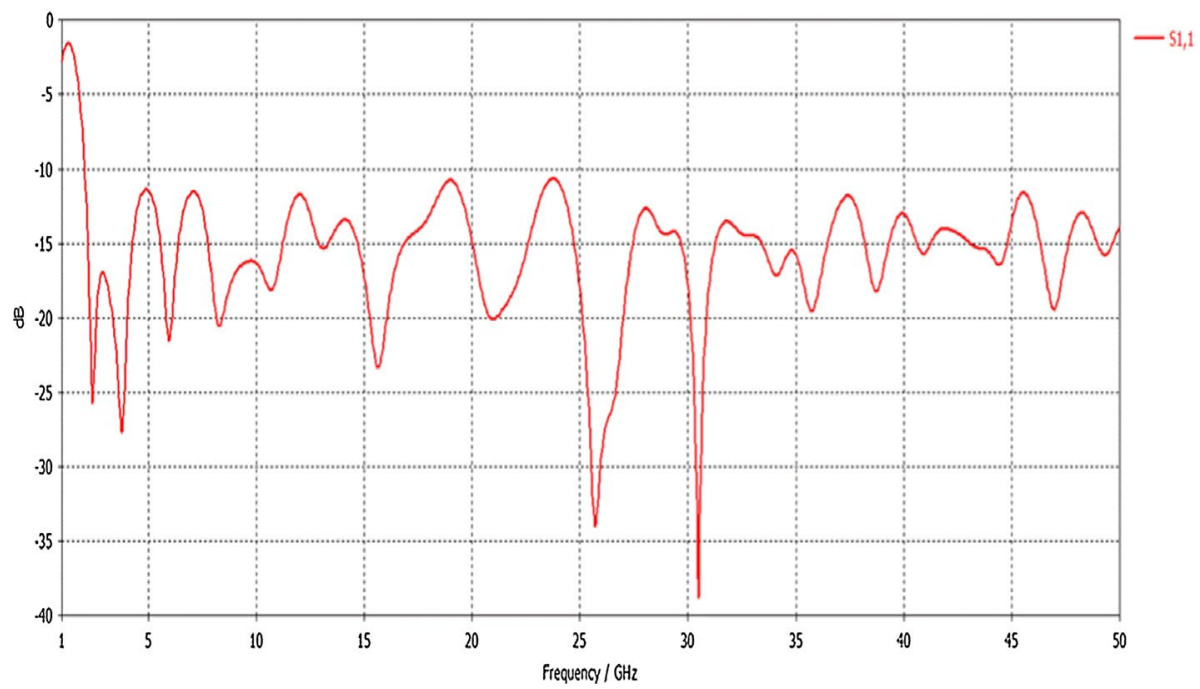

Fig. 25 Simulated S11 of the single element antenna without notch filters

Figure 26 shows the simulated S11 of the single element antenna with three notch filters. It can be seen that theoretically, the antenna works well (with S11 lower than -10 dB)

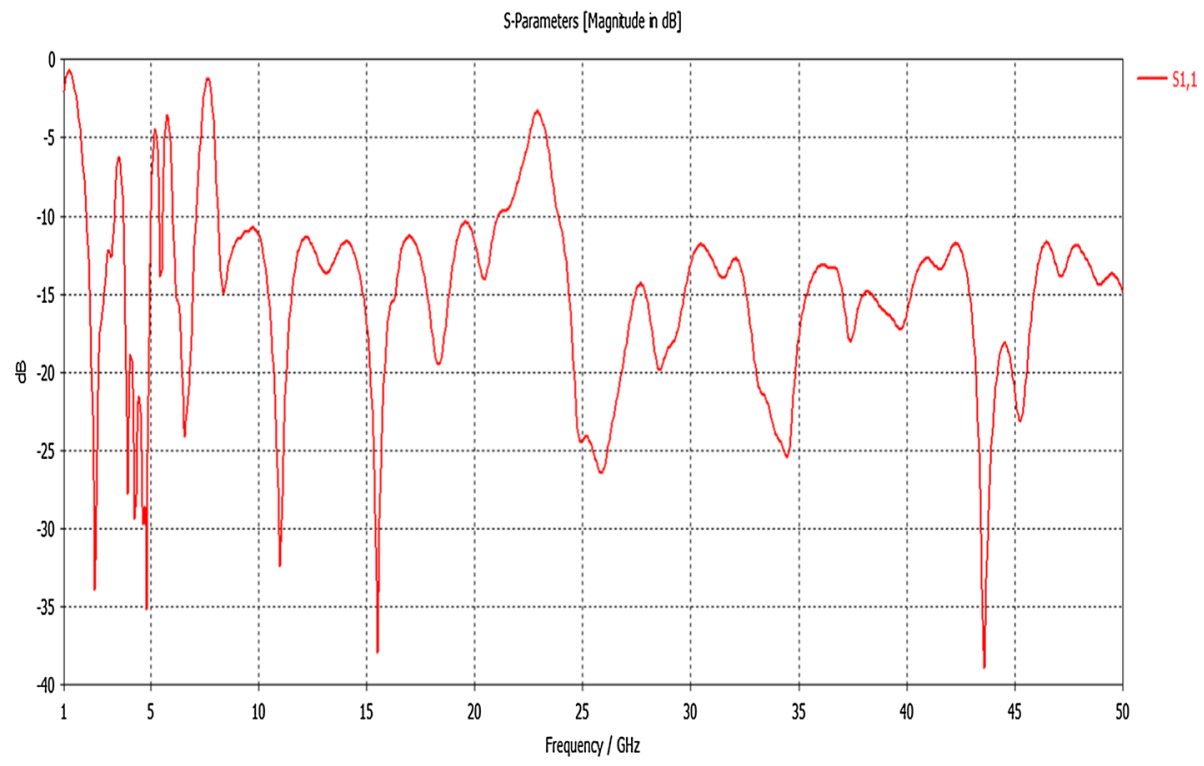

Fig. 26 Simulated S11 of the single element antenna with three notch filters 
up to $50 \mathrm{GHz}$ and it has an extra notch action near to $23 \mathrm{GHz}$ due to the third resonance of the third filter.

Funding Open Access funding provided thanks to the CRUE-CSIC agreement with Springer Nature.

\section{Declarations}

Conflict of interest The first author of the article, on his behalf and that of all the authors, declares that there is no potential conflict of interest related to the article.

Open Access This article is licensed under a Creative Commons Attribution 4.0 International License, which permits use, sharing, adaptation, distribution and reproduction in any medium or format, as long as you give appropriate credit to the original author(s) and the source, provide a link to the Creative Commons licence, and indicate if changes were made. The images or other third party material in this article are included in the article's Creative Commons licence, unless indicated otherwise in a credit line to the material. If material is not included in the article's Creative Commons licence and your intended use is not permitted by statutory regulation or exceeds the permitted use, you will need to obtain permission directly from the copyright holder. To view a copy of this licence, visit http://creativecommons.org/licenses/by/4.0/.

\section{References}

1. Federal Communications Commission revision of Part 15 of the commission's rules regarding ultrawideband transmission systems (2002) FCC, Washington, DC, First Report and Order FCC, 02 . V48.

2. Sturm, C., Porebska, M., Timmermann, J., Wiesbeck, W. (2007). Investigations on the applicability of diversity techniques in ultra-wideband radio. In Proc. Int. Conf. Electromagnetics in Advanced Applications (ICEAA). pp. 899-902.

3. Rajagopalan, A., Gupta, G., Konanur, A. S., Hughes, B., \& Lazzi, G. (2007). Increasing channel capacity of an ultrawideband MIMO system using vector antennas. IEEE Transactions on Antennas and Propagation, 55(10), 2880-2887.

4. Ben, I. M., Talbi, L., Nedil, M., \& Hettak, K. (2012). MIMO-UWB channel characterization within an underground mine gallery. IEEE Transactions on Antennas and Propagation, 60(10), 4866-4874.

5. Lee, J. M., Kim, K. B., Ryu, H. K., \& Woo, J. M. (2012). A compact ultrawideband MIMO antenna with WLAN band-rejected operation for mobile devices. IEEE Antennas Wireless Propagation Letter, 11, 990-993.

6. Hong, S., Chung, K., Lee, J., Jung, S., Lee, S. S., \& Choi, J. (2008). Design of a diversity antenna with stubs for UWB applications. Microwave and Optical Technology Letters, 50(5), 1352-1356.

7. Zhang, S., Ying, Z. N., Xiong, J., \& He, S. L. (2009). Ultrawideband MIMO/diversity antennas with a tree-like structure to enhance wideband isolation. IEEE Antennas Wireless Propagation Letter, 8, $1279-1232$.

8. See, T. S. P., \& Chen, Z. N. (2009). An ultrawideband diversity antenna. IEEE Trans. Antennas Propagation, 57(6), 1597-1605.

9. Pouyanfar, N., Ghobadi, C., Nourinia, J., Pedram, K., Majidzadeh, M., (2018). A compact multi-band MIMO antenna with high isolation for $\mathrm{C}$ and $\mathrm{X}$ bands using defected ground structure. Radioengineering, 27(3).

10. Liu, P., Sun, D., Wang, P., \& Gao, P. (2018). Design of a dual-band MIMO antenna with high isolationfor WLAN applications. Progress In Electromagnetics Research Letters, 74, 23-30.

11. Azarm, B., \& J. Nourinia, C. Ghobadi, M. Majidzadeh, N. Hatami, . (2018). A compact WiMAX band-notched UWB MIMO antenna with high isolation. Radioengineering, 27(4), 983-989.

12. Krupa Rani, D., \& Ratnam, J. V. K. (2017). UWB MIMO antenna with band-notched characteristic. International Journal on Recent and Innovation Trends in Computing and Communication., 6, 244-247.

13. Tao, J., \& Quan yuan Feng, . (2016). Compact isolation-enhanced UWB MIMO antenna with bandnotch character. Journal of Electromagnetic Waves and Applications, 30(16), 2206-2214.

14. Jaglana, N., \& b, Samir Dev Guptaa, Ekta Thakurb, Dinesh Kumarb, Binod Kumar Kanaujiac, Shweta Srivastavaa, . (2018). Triple band notched mushroom and uniplanar EBG structures based UWB 
MIMO/diversity antenna with enhanced wide band isolation. AEU - International Journal of Electronics and Communications, 90, 36-44.

15. Mewaraab, H. S., Mahendra, D. J., Jitendra, M. S., \& Deegwala, K. (2018). A printed monopole ellipzoidal UWB antenna with four band rejection characteristics. AEU - International Journal of Electronics and Communications, 83, 222-232.

16. Ahmed, B. T., Olivares, P. S., Campos, J. L. M., \& Vazquez, F. M. (2018). (3.1-20) GHz MIMO antennas. AEU - International Journal of Electronics and Communications, 94, 348-358.

17. Thomas, K. G., \& Sreenivasan, M. (2010). A simple ultrawideband planar rectangular printed antenna with band dispensation. IEEE Transactions on Antennas and Propagation, 58(1), 27-34.

18. Srivastava, G., Hoang Son, L., Kumar, R., Khari, M., A Dual band notched ultra-wideband antenna. Wireless Personal Communications, 110:1021-1032.

19. Puri, S. C., Das, S., \& Gopal Tiary, M. (2019). An UWB trapezoidal rings fractal monopole antenna with dual-notch characteristics. The International Journal of RF and Microwave Computer-Aided Engineering, 29(8), 1-10.

20. Koteswara Rao Devana, V. N., Maheswara Rao, A. (2020) Design and analysis of dual band-notched uwb antenna using a slot in feed and asymmetrical parasitic stub. IETE Journal of Research, on-line.

21. Hammache, B., Messai, A., Messaoudene, I., \& Denidni, T. A. (2019). A compact ultra-wideband antenna with three C-shaped slots for notched band characteristics. Microwave and Optical Technology Letters, 61, 275-279.

Publisher's Note Springer Nature remains neutral with regard to jurisdictional claims in published maps and institutional affiliations.

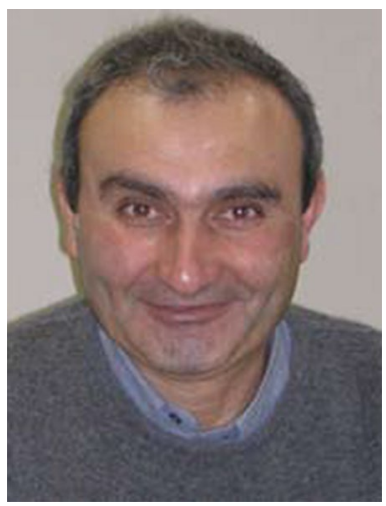

Bazil Taha Ahmed was born in Mosul, Iraq, in 1960. He received the B.Sc. and M.Sc. degrees in Electronics and Telecommunication Engineering from the University of Mosul, in 1982 and 1985, respectively. He got the D. E. A. and the Ph. D degree both in Telecommunication Engineering from the Polytechnic University of Madrid in 2001 and 2003 respectively. Now he is working as an Associate Professor at the Universidad Autonoma de Madrid. He has published more than 120 scientific journal and conference papers in the area of the electromagnetic propagation and Telecommunication systems. 